\title{
Seizure Initiation and Propagation in the Pilocarpine Rat Model of Temporal Lobe Epilepsy
}

\author{
Moran Furman \\ Department of Neurology, Yale University School of Medicine, New Haven, Connecticut 06510 \\ Review of Toyoda et al.
}

Temporal lobe epilepsy (TLE) is the most common type of epilepsy in adulthood. It is characterized by seizures originating from the limbic system, particularly the hippocampus, parahippocampal regions, and amygdala. TLE is frequently associated with an initial precipitating injury such as perinatal hypoxia, febrile seizure, infection, or head trauma. Occasionally the precipitating injury includes status epilepticus (SE), an acute, prolonged seizure typically involving convulsions and loss of consciousness. The precipitating injury is usually followed by a seizure-free latent period, and eventually the appearance of recurrent seizures (French et al., 1993).

Animal models of TLE have been instrumental in clarifying the pathophysiology of epilepsy and in the development of antiepileptic drugs and other treatments. The pilocarpine model of TLE belongs to a group of animal models that replicate the general progression of events as observed in humans, and it has been used frequently since its introduction 30 years ago (Turski et al., 1983). In this model, systemic injection of the convulsant pilocarpine induces SE, likely through activation of M1 muscarinic receptors, followed

Received Aug. 29, 2013; revised Sept. 16, 2013; accepted Sept. 17, 2013. M.F. is supported in part by a postdoctoral fellowship from the Epilepsy Foundation. I thank Dr. Hal Blumenfeld and members of the Blumenfeld laboratory for their helpful comments.

Correspondence should be addressed to Moran Furman, 789 Howard Avenue, CB661, New Haven, CT 06510. E-mail: moran.furman@yale.edu. DOI:10.1523/JNEUROSCI.3687-13.2013

Copyright $\odot 2013$ the authors $\quad 0270-6474 / 13 / 3316409-03 \$ 15.00 / 0$ by a seizure-free latent period, and eventually the appearance of recurrent seizures that continue for the rest of the animal's life.

Seizure initiation and propagation in human TLE has been examined extensively, because this information is crucial for resective surgeries aimed at treating uncontrolled seizures. In contrast and somewhat surprisingly, until recently relatively little was known about seizure initiation and propagation in the pilocarpine rat model of TLE. Toyoda at al. (2013) aimed to address this knowledge gap using simultaneous electrophysiological recordings from several brain regions. These experiments revealed important and interesting aspects of seizure spread in one of the most widely used animal models of epilepsy.

Toyoda et al. (2013) examined spontaneous seizures in 10 pilocarpine-treated rats, using local-field-potential recordings and video monitoring. Bipolar recording electrodes were implanted bilaterally in eight brain regions. Target regions were selected in part based on previously reported neuropathological changes in humans and/or rats. Using video monitoring, behavioral severity of each seizure was ranked on a standard 0-5 Racine scale. Seizure onset in each recording site was identified using four measures: one subjective "by eye" evaluation, blinded to brain regions; and three measures based on objective computerized algorithms. For each seizure and each electrode, the earliest of the four onset measures was used as the final estimate of seizure onset.

Toyoda et al.'s (2013) effort of simultaneous recordings from a large number of brain regions is notable. What are the advances gained by this improved spatial coverage? Most critically, the recordings provide accurate maps of seizure onset times among the recorded brain regions. This is important because some of the controversies regarding the validity of the pilocarpine model and its relevance to human TLE revolved around seizure onset regions. Toyoda et al. (2013) identify limbic structures, primarily the hippocampus, amygdala, subiculum, and entorhinal cortex, as the sites of seizure initiation (Toyoda et al., 2013, their Fig. 4), strengthening the validity of the model in this respect. The authors also introduce an elegant technique for visualization and analysis of seizure spread (Toyoda et al., 2013, their Figs. 5, 6). This analysis suggests that seizure initiation varies considerably within and between rats, in terms of both brain region and laterality. Similarly, sites of earliest recorded seizure activity vary between TLE patients, although interestingly, compared with rats, each patient's seizures seem to have a much more uniform onset location. Spencer et al. (1999), for instance, found that $86 \%$ of each patient's seizures had a uniform location and spatial extent of initial EEG change at seizure onset.

The overall picture emerging from Toyoda et al. (2013) and previous studies is that seizure spread across brain regions 


\begin{tabular}{|c|c|c|}
\hline & $\begin{array}{l}\text { Pilocarpine rat } \\
\text { model (in } \\
\text { seconds) }\end{array}$ & $\begin{array}{l}\text { TLE patients } \\
\text { (in seconds) }\end{array}$ \\
\hline Average seizure duration & $40-90^{a, b, c}$ & $110-120^{d, e, f, g}$ \\
\hline $\begin{array}{l}\text { Average latency from } \\
\text { electrographic to } \\
\text { behavioral seizure } \\
\text { onset }\end{array}$ & $\sim 5^{a}$ & $16-19^{h, i}$ \\
\hline $\begin{array}{l}\text { Average spread time to } \\
\text { contralateral } \\
\text { hemisphere }\end{array}$ & $\sim 2^{a}$ & $20-30^{i j, j k}$ \\
\hline $\begin{array}{l}\text { Average spread time } \\
\text { across brain regions }\end{array}$ & $\sim 7^{a}$ & $17-30^{d, e, h, i, l}$ \\
\hline
\end{tabular}

Entries represent approximate average value (for single study) or range of average values across studies. For detailed references, see: ${ }^{a}$ Toyoda et al. 2013; ${ }^{b}$ Lévesque et al., 2012; Englot et al., 2008; ${ }^{d}$ Brekelmans, 1995; ${ }^{e}$ Spencer et al., 1999; ${ }^{f}$ Afra et al., 2008; ${ }^{9}$ Zangaladze et al., 2008; ${ }^{h}$ Götz-Trabert et al., 2008; 'Quesney, 1986; 'Spencer et al., 1992; ' Spanedda et al., 1997; 'Spencer et al., 1987.

in the pilocarpine model is faster than in human patients (Table 1). These differences between rats and humans may relate to differences in brain anatomy and connectivity, such as hemispheric lateralization, brain size, and more, as discussed by Toyoda et al. (2013) in the concluding section of their article.

Does the faster seizure spread in pilocarpine-treated rats compared with humans compromise the validity of the pilocarpine model? One may argue that the crucial point is not to generate an animal model completely homologous to the human disease, which in fact is next to impossible given TLE's extremely diverse etiology and pathophysiology. More important is being able to correctly and reliably interpret findings from animal experiments, to provide a sound link between the pathophysiology of the disease and its syndromes, and to facilitate effective identification and development of treatments. In this respect, the work by Toyoda et al. (2013) represents a valuable step forward, as it significantly narrows the knowledge gap regarding seizure initiation and propagation in the pilocarpine model.

A limitation of the study by Toyoda et al. (2013), inherent to existing electrophysiological recording techniques, is the limited spatial coverage of the recordings. This has several important implications. First, the possibility remains that some seizures in the pilocarpine model are initiated in brain regions other than those tested by Toyoda et al. (2013), for example, different parts of the neocortex, as occurs in some patients. Second, it is possible that focusing on a specific sample of brain regions, mostly subcortical, resulted in overestimating the number of generalized seizures. In other words, partial temporal lobe seizures, which are quite common in patients, could be classified as generalized when focusing on brain regions more prone to seizure propagation. In a previous study, Englot et al. (2008) classified seizures into partial versus generalized using recordings from the orbitofrontal cortex. They found that $76 \%$ of the seizures were generalized, compared with 95\% in Toyoda et al. (2013). The spatial coverage of brain regions was more limited in Englot et al. (2008) compared with Toyoda et al. (2013), but since the orbitofrontal cortex is a brain region remote from the mesial temporal lobe, classifying seizures based on it may provide a more conservative estimate of the number of electrographically generalized seizures. However, seizures in the two studies differed not only electrographically but also behaviorally: $37 \%$ compared with $76 \%$ of the seizures caused generalized convulsions in Englot et al. (2008) versus Toyoda et al. (2013), respectively. Although electrographically generalized seizures do not always cause generalized convulsions, the behavioral data does argue for an actual difference in the fraction of generalized seizures between the two studies, and not only a methodological difference resulting from sampling different brain regions. It is likely, therefore, that other methodological details further contributed to these differences. In fact, seizure properties in the pilocarpine model have been shown to vary to some extent depending on details such as pretreatment procedures [atropine vs scopolamine in Toyoda et al. (2013) and Englot et al. (2008), respectively], animal age, and more (Curia et al., 2008).

One way to address the limited spatial coverage of traditional electrophysiological recordings is to use functional imaging. Advances in high-field functional magnetic resonance imaging (fMRI) techniques in rodents allow brain-wide imaging at a high spatial resolution, which can complement direct recordings from targeted brain regions. For instance, using fMRI, electrophysiological recordings, and cerebral blood flow measurements, Englot et al. (2009) found reduced cortical metabolism during partial hippocampal seizures, concurrent with large-amplitude slow-wave (1-2 Hz) activity in the frontal cortex, as previously observed in patients during complex partial seizures. This cortical slow-wave activity may be caused by inhibition of subcortical arousal circuits, and is likely mechanistically linked to impaired consciousness during seizures (Blumenfeld, 2012).

Whereas using fMRI to complement direct electrophysiological recordings is valuable, a number of caveats of fMRI are particularly important in the context of seizure measurement: (1) it reflects neural activity indirectly; (2) it has low temporal resolution; and (3) the need to immobilize the animal prevents behavioral analysis of seizure severity during brain scans, and also limits the duration of experiments compared with freely behaving animals. Thus, the challenges in monitoring seizure initiation and spread faced by both clinicians and researchers underscore the need for new, minimally invasive techniques to record widespread neural activity across the brain (Alivisatos et al., 2013). In the mean time, putting existing techniques to the best of their use, as exemplified by the valuable study of Toyoda et al. (2013), supports the continuous advancement toward better understanding of seizure propagation and new treatments of epilepsy.

\section{References}

Alivisatos AP, Chun M, Church GM, Deisseroth K, Donoghue JP, Greenspan RJ, McEuen PL, Roukes M, Sejnowski TJ, Weiss PS, Yuste R (2013) The brain activity map. Science 339: 1284-1285. CrossRef Medline

Afra P, Jouny CC, Bergey GK (2008) Duration of complex partial seizures: an intracranial EEG study. Epilepsia 49:677-684. CrossRef Medline

Blumenfeld H (2012) Impaired consciousness in epilepsy. Lancet Neurol 11:814-826. CrossRef Medline

Brekelmans G, van Emde Boas W, Velis D, Van Huffelen A, Debets R, Van Veelen C (1995) Mesial temporal versus neocortical temporal lobe seizures: demonstration of different electroencephalographic spreading patterns by combined use of subdural and intracerebral electrodes. J Epilepsy 8:309-320. CrossRef

Curia G, Longo D, Biagini G, Jones RS, Avoli M (2008) The pilocarpine model of temporal lobe epilepsy. J Neurosci Methods 172:143157. CrossRef Medline

Englot DJ, Mishra AM, Mansuripur PK, Herman P, Hyder F, Blumenfeld H (2008) Remote effects of focal hippocampal seizures on the rat neocortex. J Neurosci 28:9066-9081. CrossRef Medline

Englot DJ, Modi B, Mishra AM, DeSalvo M, Hyder F, Blumenfeld H (2009) Cortical deactivation induced by subcortical network dysfunction in limbic seizures. J Neurosci 29: 13006-13018. CrossRef Medline

French JA, Williamson PD, Thadani VM, Darcey TM, Mattson RH, Spencer SS, Spencer DD (1993) Characteristics of medial temporal lobe epilepsy: I. Results of history and physical examination. Ann Neurol 34:774-780. CrossRef Medline

Götz-Trabert K, Hauck C, Wagner K, Fauser S, Schulze-Bonhage A (2008) Spread of ictal 
activity in focal epilepsy. Epilepsia 49:15941601. CrossRef Medline

Lévesque M, Salami P, Gotman J, Avoli M (2012) Two seizure-onset types reveal specific patterns of high-frequency oscillations in a model of temporal lobe epilepsy. J Neurosci 32: 13264-13272. CrossRef Medline

Quesney L (1986) Clinical and EEG features of complex partial seizures of temporal lobe origin. Epilepsia 27:S27-S45. CrossRef Medline

Spanedda F, Cendes F, Gotman J (1997) Relations between EEG seizure morphology, interhemispheric spread, and mesial temporal atrophy in bitemporal epilepsy. Epilepsia 38: 1300-1314. CrossRef Medline
Spencer SS, Williamson PD, Spencer DD, Mattson RH (1987) Human hippocampal seizure spread studied by depth and subdural recording: the hippocampal commissure. Epilepsia 28:479-489. CrossRef Medline

Spencer SS, Marks D, Katz A, Kim J, Spencer DD (1992) Anatomic correlates of interhippocampal seizure propagation time. Epilepsia 33:862-873. CrossRef Medline

Spencer SS, Kim J, deLanerolle N, Spencer DD (1999) Differential neuronal and glial relations with parameters of ictal discharge in mesial temporal lobe epilepsy. Epilepsia 40: 708-712. CrossRef Medline

Toyoda I, Bower MR, Leyva F, Buckmaster PS
(2013) Early activation of ventral hippocampus and subiculum during spontaneous seizures in a rat model of temporal lobe epilepsy. J Neurosci 33:11100-11115. CrossRef Medline

Turski WA, Cavalheiro EA, Schwarz M, Czuczwar SJ, Kleinrok Z, Turski L (1983) Limbic seizures produced by pilocarpine in rats: behavioural, electroencephalographic and neuropathological study. Behavioural brain research 9:315-335. CrossRef Medline

Zangaladze A, Nei M, Liporace JD, Sperling MR (2008) Characteristics and clinical significance of subclinical seizures. Epilepsia 49: 2016-2021. CrossRef Medline 